Virginia L. Byrne

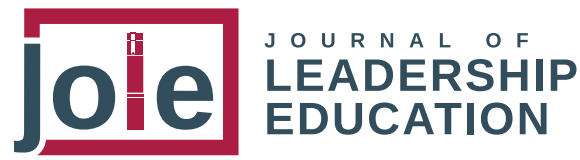

JANUARY 2022

RESEARCH SECTION
Morgan State University

Hannah E. Jardine

The Catholic

University of America
Alexis Y. Williams

University of Maryland,

College Park

Alice E. Donlan

University of Maryland,

College Park

\title{
ACADEMIC PEER MENTORSHIP AS A LEADERSHIP DEVELOPMENT EXPERIENCE:
}

\section{Fostering Leadership Self-Efficacy}

\section{Abstract}

Undergraduate academic peer mentors gain a deeper understanding of the academic content and develop professional teaching and coaching skills. While the value of this high impact practice is well documented for academic outcomes, little is known about the leadership self-efficacy that results from serving as an academic peer mentor. In this initial quantitative study of a cross-disciplinary academic peer mentoring program for 79 American undergraduates, we found that after serving as an academic peer mentor, students reported higher self-efficacy for leading groups. Academic peer mentorship programs show promise as a leadership development opportunity for college students.

\section{Introduction}

Undergraduates who serve as academic peer mentors (APMs) partner with instructors to support active learning and high-touch classroom experiences for students. In their role as an APM, they gain a new proficiency of the academic content and develop professional skills as a teacher and coach (Amaral \& Vala, 2009; Dunn \& Moore, 2020; Philipp et al., 2016). Through leading small group discussions, study sessions, and activities, as well as working closely with a faculty member, APMs may also develop as leaders and problem solvers (e.g., Jardine \& Friedman, 2017; Schalk et al., 2009). Existing research has focused mostly on outcomes for APMs related to their academic achievement and identity development as a role model (Skipper \& Keup, 2017). However, these works have rarely applied constructs from the leadership education and development literature to gain a deeper understanding of the outcomes for APMs. To address this gap, in our initial quantitative study of 79 undergraduate academic peer mentors, we draw from the leadership literature (e.g., Dugan \& Komives, 2010) to explore if participating in an APM program contributes to students' development of self-efficacy for leading groups, i.e., students' beliefs about their "abilities to exercise their leadership knowledge and skills in a given situation" (Denzine, 1999, p. 3).

We contribute to the growing bodies of APM and experiential leadership learning literatures by presenting a peer mentorship program at a predominately white research university in the Mid-Atlantic U.S. and examining changes in the peer mentors' leadership self-efficacy during their experience. We conclude by demonstrating the usefulness of measuring leadership self-efficacy as a way to evaluate a novel potential benefit of participation in an academic peer mentorship 
program. In this paper, we address the research question: To what extent does participation as an APM relate to students' self-efficacy for leadership? To answer this question we analyzed the difference in APM's self-reported leadership self-efficacy between the beginning and the end of their first semester in the program. Based on our review of the literature, we hypothesized that by serving as an APM, students would gain experiences presenting to, coordinating, and leading groups of their peers, and thus would develop a sense of efficacy for leading groups in the future. We pose that academic peer mentorship programs show promise as a leadership learning opportunity for college students.

\section{Review of Related Literature}

Our work builds upon and connects the academic peer mentorship and the leadership self-efficacy literatures to pose a theoretical framework for how experiential service in an academic context, with formal mentorship and reflection components, can support students' development of efficacy for leading groups. We present brief reviews of the two literatures and then pose our framework.

Academic Peer Mentors. College students can engage in peer mentorship on several dimensions, one of which is academic support (Nora \& Crisp, 2007). In this study, we focus on the experience of Academic Peer Mentors (APMs), undergraduates who work alongside course instructors in a variety of disciplines and classroom contexts to support active learning through interacting with students and helping with instructional planning, facilitation, and design. APMs fill roles like those documented in the learning assistant (Otero et al., 2010), peer-led team learning (Gafney \& Varma-Nelson, 2008), and peer learning assistant (Groccia \& Miller, 1996) literatures, or other literatures that use terms such as undergraduate teaching assistant, peer educator, or peer facilitator. Although APMs in different courses and disciplines may have differing responsibilities, they all mentor other undergraduate students in an academic course.

There are several beneficial outcomes for undergraduates serving as APMs. Most research focuses on the cognitive benefits, stemming from the longstanding notion that peer teaching leads to greater learning (Johnson \& Johnson, 1975). Through mentoring other students, APMs gain a deeper understanding of the course content (Gafney \& Varma-Nelson, 2007), earn higher grades in subsequent coursework (Amaral \& Vala, 2009), and develop metacognitive learning strategies (Jardine \& Friedman, 2017). They also experience personal and professional development (Micari et al., 2005; Philipp et al, 2016), including gaining teaching skills and a greater interest in teaching (Glover et al., 2017; Gray \& Otero, 2008; Tenney \& Houck, 2004).

Leadership Self-Efficacy. The nascent leadership self-efficacy literature builds on Bandura's (1997) concept of self-efficacy as a theoretical framework for explaining and predicting performance based on self-perceptions. Perceived self-efficacy does not measure "the number of skills you have, but with what you believe you can do with what you have under a variety of circumstances" (Bandura, 2006, pg. 37). Self-efficacy has been found to be a powerful predictor of future action, even in new contexts (Bandura, 2006). Increasingly self-efficacy is being used in professional development and adult learning contexts in which knowledge and skills must be applied to future action.

Participants who have completed a leadership development program are often assessed with selfreported measures of leadership-related knowledge and skills (see Rosch, 2018). However, these 
measures too narrowly focus on what the student knows and has experienced in-the-moment as opposed to predicting what they can achieve in the future. These measures fall short of understanding if the program has prepared the participant to have the confidence to enact what they have learned in the future. As Bandura (1997) found, self-efficacy interacts with a person's knowledge and skills to lead some people to believe they can perform successfully while others believe they will fail.

In Rosch's (2018) critique of existing leadership training programs, he posed the use of the "Ready, Willing, and Able" model of leadership education authored by Keating, Rosch, and Burgoon (2014) which argues that students should be supported in developing the self-efficacy (i.e., "Ready"), motivation ("Willing"), and skills to lead ("Able"). The balance of these three aspects is essential for preparing students to lead in their future endeavors. In their development of the leadership self-efficacy scale, Dugan and Komives (2010), argue that the outcome of college and leadership development programs is to prepare students for future situations of leadership. Leadership efficacy, defined by Dugan and Humbles (2018) as "Internal beliefs about whether one would be successful when engaging in leader roles and/or leadership processes" (pg. 20), is important for the development of a readiness to lead (Keating et al, 2014), motivation to lead (Correia-Harker \& Dugan, 2020), and is one of the four dimensions of Critical Leadership Development (Dugan \& Humbles, 2018). For these reasons, leadership self-efficacy is an appropriate outcome variable of college learning experiences that engage the student in real-life leadership opportunities.

Theoretical Framework. Prior research has found that through experiential learning and participation in high-impact practices, such as service-learning and faculty mentorship, students develop new knowledge, skills, and values, as well as self-efficacy for accomplishing future related challenges (e.g.,
Kuh, 2008). Similarly, students develop as leaders through hands-on experiences with space and processes for reflection, feedback, and mentorship (e.g., Soria \& Johnson, 2017). We pose that because the APM program (as we will present in detail in the following section) positions students in a novel situation of leading and teaching their peers (with formalized mentorship, reflection, and feedback processes), the students would be able to grow as leaders and gain confidence and self-efficacy to lead future peer groups.

\section{Methods}

We present an overview of our Academic Peer Mentoring program and methods from our initial study of the extent to which participants develop leadership self-efficacy.

\section{Application Description. The Academic Peer} Mentoring program explored in this study supports the integration of select undergraduates, APMs, into courses to work with university instructors, as part of a team, to promote more active, student-centered instruction. Course instructors enroll in the program and then recruit students who have demonstrated subject mastery in their course and are dedicated to working directly with other students. APMs support student learning across disciplines and classroom contexts, including course-based undergraduate research experiences (Auchincloss et al., 2014), large introductory STEM courses, and small upperlevel humanities and social science courses. Thus, APMs fulfill a wide range of responsibilities including working with students one-on-one and in small groups, helping with course logistics, communicating with students outside of class, and providing instructors with feedback and support in developing instructional materials. The fourth author of this paper developed the program initially, and the second author managed the program during the data collection in this study. 
In this program, APMs take a one-credit course during their first semester in the role, Fundamentals of Academic Peer Mentoring, to introduce them to theories of education and support them as they develop teaching, mentorship, and leadership skills. The class is blended, with face-to-face meetings every third week and asynchronous learning modules during the remaining weeks. During the meetings students engaged in hands-on activities and discussions, while the online weeks focus on individual learning and reflections, as well as building their final mentorship portfolio. The course was designed to be blended to better accommodate the busy schedules of the student leaders we aimed to recruit to the APM program.

The course is designed as a professional learning community aligned, in part, with teacher professional development literature (e.g., DeSimone, 2009) and experiential, service-learning programs (e.g., Jacoby, 1996). The learning community focuses on the common goal of developing as teachers and peer leaders, but activities provide opportunities for individualized reflection that connects the content to students' specific APM responsibilities.

The course supports peer mentors' pedagogical development by encouraging reflection on their teaching as they read scholarship of teaching and learning, similar to that of Otero et al. (2010), but also explicitly introduces APMs to topics related to leadership development and opportunities to practice their leadership skills in the face-to-face meetings. At the beginning of the APM experience, students set personal and professional development goals. Facilitators scaffold this goal-setting process with readings and reflection activities on having a Growth Mindset (e.g., Dweck, 2016). Throughout the semester, APMs are encouraged to reflect on their goals and collect evidence demonstrating how they have worked towards their goals. Additionally, students write a Mentorship Philosophy Statement in which they reflect on their beliefs about mentorship and their guiding principles as a mentor.

During the face-to-face meetings, APMs engage in active learning scenarios and discussions about issues related to mentorship. For example, early in the semester, APMs discuss in small groups how they would respond to different challenging scenarios that they might experience in their mentorship role. The course culminates in the submission of a Mentorship Portfolio, which includes the Mentorship Philosophy Statement, evidence of mentorship learning aligned with their personal and professional goals, and a final reflection which asks them to reflect on their growth and development as leaders and mentors, areas of continued development, and how this experience has supported or influenced long-term career and professional goals.

The course learning outcomes are:

1. Explain fundamental, evidence-based concepts about teaching, learning, and peer mentorship, and apply those concepts to their role as an APM and as a student

2. Gather and analyze feedback from students, the instructional team, coaches in the University's Teaching and Learning Center, and other APMs for the purpose of improving mentorship practice and documenting effectiveness

3. Create a mentorship portfolio that demonstrates progress towards mentorship goals and critical reflection on knowledge, skills, and experience developed through the experience

By responding to purposefully designed discussion and reflection prompts and creating a mentorship portfolio, APMs connect their mentorship work to the topics covered in the course, which further supports their leadership self-efficacy development. For the online assignments, after the APMs are introduced to a new topic, they answer open-ended questions about the content, as well as a question about the application of that content to their role and the work they do with instructors, "What do you plan to share with your instructional team regarding [TOPIC]?" For each portfolio component due over the semester, APMs receive feedback from 
others in the course through a randomized peerreview process. Table 1 lists the course topics and assignments by week. The APM course and program highlight the role of APMs as a bridge between instructors and students, and reiterate the critical role that APMs play in improving student learning and providing feedback to course instructors.

\section{Table 1}

Course Topics and Assignments by Week

\begin{tabular}{|l|l|l|}
\hline Week & Topic & Assignments \\
\hline 1 & Introduction to Mentorship and Goal Setting & Portfolio Introduction \\
\hline 3 & Learning Outcomes & Online assignment \\
\hline 4 & Responding to Common Challenging Scenarios & Attend face to face meeting \\
\hline 5 & Active and Student-Centered Learning Strategies & Online assignment \\
\hline 6 & Discussion and Questioning Techniques & Online assignment \\
\hline 7 & Peer Critique of Mentorship Philosophy Statement & Online assignment \\
\hline 8 & Communication and Feedback & Attend face to face meeting \\
\hline 9 & Spring Break & \\
\hline 10 & Motivation and Mindset & Online assignment \\
\hline 11 & Metacognition and Self-Regulated Learning & Online assignment \\
\hline 12 & Evidence of Mentorship & Online assignment \\
\hline 13 & Celebration of Leadership & $\begin{array}{l}\text { Portfolio evidence of mentorship } \\
\text { effectiveness }\end{array}$ \\
\hline 14 & Reflection & Attend face to face meeting \\
\hline 15 & Final Portfolio & Prepare Final Portfolio \\
\hline
\end{tabular}

Data Collection. This study was conducted at a large, research university in the Mid-Atlantic USA. The authors represent the two sides of this project: implementation and evaluation. The evaluation team has no contact with the APMs other than during data collection and is not affiliated with their pedagogy course or supervision. The two authors representing the evaluation team collected preand post-test data from the APMs in the Spring of 2019. At the beginning and end of the semester, the researchers attended face-to-face meetings and sent in-course online messages through the Learning Management System to recruit students to complete the online Qualtrics survey. The researchers informed the APMs that their individual responses to the online surveys would not be shared with their APM teachers or supervisors. Participation in the study was voluntary. This study was approved by our university's Institutional Review Board.

Participants. Of the approximately 225 students participating in the APM program enrolled in the Fundamentals of Peer Mentoring Course in Spring 2019, 105 completed the pre-test and 169 completed the post-test, and 79 students completed both surveys. As demonstrated in Table 2, the 79 APMs in our paired sample were mostly women and white (which was expected based on the 
University's overall enrollment and the general APM cohort). This APM sample was majority sophomores because they were recruited to support courses for first-year students which they had taken in the previous year. Students represented most of the majors and programs from across the University and were recruited to represent a variety of student engagement pathways (e.g., pre-med). All students were in their first semester in the APM program.

\section{Table 2}

Demographic Information of the Students Who Completed Both Surveys

\begin{tabular}{llll} 
Variable & Group & N & \% Sample \\
Gender Identity & Man & 24 & $30.38 \%$ \\
& Other & 1 & $1.27 \%$ \\
& Woman & 51 & $64.56 \%$ \\
Year in School & First Year & 7 & $8.86 \%$ \\
& Sophomore & 39 & $49.37 \%$ \\
& Junior & 15 & $18.99 \%$ \\
Race/ & Senior & 15 & $18.99 \%$ \\
Ethnicity & American Indian and Indigenous & 0 & $0 \%$ \\
& Asian American or Pacific Islander & 21 & $26.58 \%$ \\
& Black or African American & 5 & $6.33 \%$ \\
& Latinx & 2 & $2.53 \%$ \\
& Multi & 3 & $3.80 \%$ \\
& Other & 3 & $3.80 \%$ \\
& White & 37 & $46.84 \%$ \\
\hline
\end{tabular}

Instrument. We adopted Dugan and Komives's (2010) Self-Efficacy for Leadership scale which was developed based on Bandura's (1997) original guidelines for designing valid and reliable measures of self-efficacy. The 4-item scale measures students' self-reported responses using a Likert scale ranging from (1) "Not at all Confident" to (6) "Very Confident." Additionally, our survey collected students' demographic information, including gender identity, year in school, and race and ethnic identity.

Analysis. First, after conducting $t$-tests in SPSS 24 , we determined that there were no significant differences between our sample of 79 students who took both surveys and the full APM cohort with regard to the Self-Efficacy for Leadership variables. Our analyses then focused specifically on the 79 students in our sample.

We conducted Shapiro-Wilk tests of normality and found evidence that the sampling distribution of the individual items and aggregated leadership selfefficacy variables were normally distributed $(p>.05)$. We then assessed the reliability of the leadership self-efficacy scale using Cronbach's alpha (Raykov \& Marcoulides, 2011). We paired students' preand post-tests using their university identification number. We averaged each students' responses for 
the four items into two aggregate scales: leadership self-efficacy pre-test and post-test. The analysis of Cronbach's alpha for the aggregate scales at both time points resulted in good scale reliability: pretest $\alpha=.85$, post-test $\alpha=.91$. These results indicate good reliability of the instrument for measuring leadership self-efficacy within this context. We conducted descriptive, correlational, and paired sample t-tests to answer our research question.

\section{Program Outcomes}

We found that after serving as an APM for one semester, students reported a higher leadership self-efficacy than they did at the beginning of the semester. We conducted a paired-samples $t$-test of the 79 students who completed both surveys to determine whether there was a statistically significant mean difference between before and after serving as an APM.

As presented in Table 3, students reported statistically significantly higher post-test responses to the individual items of efficacy for "Leading Others" and "Organizing Group Tasks to Accomplish a Goal" ( $p<.01)$, suggesting significant gains in these two aspects of leadership self-efficacy during their APM semester. While students were found to report gains on the other two items, "Taking Initiative to Improve Something" and "Working with a Team on a Group Project," these gains were not significant at the .05 level.

Overall, APM students reported significantly higher end-of-semester leadership self-efficacy responses $(M=5.15)$ than at the beginning of their APM semester $(M=4.88)$. We observed a significant preto post-test gain of $|.27|$ among our sample of 79 APMs ( $(95 \% \mathrm{Cl},-.44$ to -.11$), t(78)=-3.25, p=.002$, Cohen's $d=.31)$. To better understand this gain in leadership self-efficacy, we conducted a Pearson Correlation test and found that the pre- and posttest aggregate leadership self-efficacy variables were statistically significantly positively correlated at the 0.01 level $(r(77)=.61, p<.01)$. These findings suggest that during their APM semester, students gained leadership self-efficacy specifically in regards to "Leading Others" and "Organizing Group Tasks to Accomplish a Goal," which aligned with our hypotheses because these are two main APM duties. The APM program explicitly focuses on helping APMs develop confidence and skills related to leading others through teaching and facilitating small-group learning activities. APMs were less likely to be asked to make program improvements or work on a group project which is why these two items may not have been significantly different between the beginning and end of the semester.

We interpret these findings to mean that the APM program has the potential to, like other high impact practices (e.g., Kuh, 2008; Soria \& Johnson, 2017), positions students in roles and scenarios in which they gain experience leading groups and thus develop confidence and efficacy to lead groups in the future. In line with similar programs (e.g., Otero et al., 2010), we believe that it may be the combination of practicing teaching through working with students, developing a relationship with a course instructor, and participating in a training course that provides pedagogical support, that lead to cognitive, personal, and professional development, including growth in leadership selfefficacy. Although the findings suggest academic peer mentoring is associated with increased leadership self-efficacy, we cannot confidently isolate any specific aspects of the program as the reason without future investigations (as identified in our limitations section below). 
Table 3. Descriptive and Paired t-test Statistics for Pre- and Post-Test Leadership Self-Efficacy Items and Aggregate

\begin{tabular}{|c|c|c|c|c|c|c|c|}
\hline & \multicolumn{2}{|c|}{ Pre-Test } & \multicolumn{2}{|c|}{ Post-Test } & \multirow[b]{2}{*}{ Paired $t$-test } & \multicolumn{2}{|c|}{ Confidence Interval } \\
\hline & M & SD & M & SD & & Lower & Upper \\
\hline Leading Other & 4.61 & 1.16 & 5.04 & 0.99 & $-4.24^{* \star}$ & -0.63 & -0.23 \\
\hline $\begin{array}{l}\text { Organizing Group Tasks to } \\
\text { Accomplish a Goal }\end{array}$ & 4.85 & 0.98 & 5.16 & 0.91 & $-3.08 * \star$ & -0.52 & -0.11 \\
\hline $\begin{array}{l}\text { Taking Initiative to Improve } \\
\text { Something }\end{array}$ & 4.94 & 1.03 & 5.11 & 0.99 & -1.50 & -0.41 & 0.06 \\
\hline $\begin{array}{l}\text { Working with a Team on a } \\
\text { Group Project }\end{array}$ & 5.11 & 0.92 & 5.28 & 0.95 & -1.40 & -0.40 & 0.07 \\
\hline $\begin{array}{l}\text { (Aggregate) Leadership Self- } \\
\text { Efficacy }\end{array}$ & 4.88 & 0.85 & 5.15 & 0.85 & $-3.25 * \star$ & -0.44 & -0.11 \\
\hline$\star \star p<<.01$ & & & & & & & \\
\hline
\end{tabular}

\section{Recommendations}

This study reveals implications for educators who are designing and assessing APM programs. We found a potential connection between undergraduate students' participation in an APM program and significant gains in self-efficacy for leading groups. Connecting back to Keating et al.'s (2014) “Ready, Willing, Able” framework for leadership learning, is it essential for experiential learning programs to prioritize and prepare students to be "Ready" (i.e., have efficacy) to lead future teams. We recommend that leadership selfefficacy be an explicit goal of academic peer mentor programs, integrated into all three aspects of the peer mentorship experience: working with students, working with the course instructor, and participating in a training course. Our APM program, and the associated training course, provided students with ample opportunities to set personal goals, practice application of skills, reflect on their performance, share their growth with a community of other APMs, and document their accomplishments in a portfolio.

In this study, we provide an initial (though limited) demonstration of the connection between students' participation in an APM program and increased leadership self-efficacy. While alternative

leadership and life experiences might have been the cause for this gain, we maintain that APM programs should incorporate similar aspects of leadership development as part of APM training and set expectations and responsibilities that empower APMs to enact leadership when working with students. We also recommend that those who are assessing APM programs use validated quantitative instruments (e.g., Dugan \& Komives, 2010) and measures of motivation (e.g., CorreiaHarker \& Dugan, 2020) to better understand if and how students develop through participation in the program.

Limitations. Our study is limited by our singular context and the small sample size. Future research could replicate the methods at a different institution and with a larger student sample to clarify the reliability of our findings. This future work should also incorporate a critical lens to further examine trends in leadership efficacy development based on existing patterns of marginalization and silencing of Black, Latinx, and Indigenous students from student leadership programs (see Dugan \& Humbles, 2018). Additionally, future research could augment the survey findings with qualitative data 
by exploring how students describe their leadership self-efficacy in reflections and interviews, and what programmatic factors students identify as beneficial in their leadership development. Finally, future psychometric analyses should investigate if the Dugan and Komives's (2010) Self-Efficacy for Leadership Scale is at risk of a "ceiling effect" (Hessling et al., 2004) because we observed that the scale "possesses a distinct upper limit for potential responses and a large concentration of participants score at or near this limit" (pg. 106). We call for this future analysis because our data demonstrated little variance at the top of the scale range.

\section{Conclusion}

In this study, we described our academic peer mentorship program and demonstrated how participation in this program may support students in developing a "readiness" (i.e., Keating et al., 2014) or self-efficacy for leading groups in future endeavors (Dugan \& Komives, 2010). In our initial study, we applied a validated quantitative instrument, grounded in a self-efficacy theoretical framework, to better understand the leadership learning value of participating in an academic peer mentor program. By clarifying the connection between leadership self-efficacy and academic peer mentorship, we encourage educators of both types of educational programs to connect on campus and clarify to students how their engagement is part of their larger leadership education journey. 


\section{References}

Amaral, K. E., \& Vala, M. (2009). What teaching teaches: Mentoring and the performance gains of mentors. Journal of Chemical Education, 86(5), 630-633.

Auchincloss, L. C., Laursen, S. L., Branchaw, J. L., Eagan, K., Graham, M., Hanauer, D. I., ... Dolan, E. L. (2014). Assessment of course-based undergraduate research experiences: a meeting report. Cbe Life Sciences Education, 13(1), 29-40.

Bandura, A. (1997). Self-efficacy: The exercise of control. W.H. Freeman and Company.

Bandura, A. (2006). Guide for constructing self-efficacy scales. In F. Pajares \& T. C. Urdan (Eds.) Self-efficacy beliefs of adolescents (pp. 307-337). Information Age Publishing.

Correia-Harker, B. P., \& Dugan, J. P. (2020). Beyond knowledge and skills: Exploring leadership motivation as a critical construct for student leadership development. Journal of College Student Development, 61(3), 299-316.

Denzine, G. (1999). Personal and collective efficacy: Essential components of college students' leadership development. Concepts \& Connections, 8(1), 1-5.

Desimone, L. M. (2009). Improving impact studies of teachers' professional development: Toward better conceptualizations and measures. Educational Researcher, 38(3), 181-199.

Dugan, J. P., \& Humbles, A. D. (2018). A paradigm shift in leadership education: Integrating critical perspectives into leadership development. New Directions for Student Leadership, 2018(159), 9-26.

Dugan, J. P., \& Komives, S. R. (2010). Influences on college students' capacities for socially responsible leadership. Journal of College Student Development, 51(5), 525-549.

Dunn, A. L., \& Moore, L. L. (2020). Significant learning of peer mentors within a leadership living-learning community: A basic qualitative study. Journal of Leadership Education, April.

Dweck, C. (2016). What having a "growth mindset" actually means. Harvard Business Review, 13, 213-226.

Gafney, L., \& Varma-Nelson, P. (2007). Evaluating peer-led team learning: A study of long-term effects on former workshop peer leaders. Journal of Chemical Education, 84(3), 535-539.

Gafney, L., \& Varma-Nelson, P. (2008). Peer-led team learning: Evaluation, dissemination, and institutionalization of a college level initiative (Vol. 16). Springer Science \& Business Media.

Glover, R., Hammond, N.B., Smith, J. \& Guerra, D. (2018). Assessing peer leader skill acquisition and group dynamics in a first-year calculus course. International Journal for the Scholarship of Teaching and Learning, 12(1), ar10.

Gray, K. E., \& Otero, V. K. (2008). Analysis of learning assistants' views of teaching and learning. In AIP Conference Proceedings, 1064(1), 123-126. AIP.

Groccia, J. E., \& Miller, J. E. (1996). Collegiality in the classroom: The use of peer learning assistants in cooperative learning in introductory biology. Innovative Higher Education, 21(2), 87-100. 
Hessling, R. M., Traxe, N. M. \& Schmidt, T. J. (2004) Ceiling effect. In M. S. Lewis-Beck, A. Bryman, \& T. F. Liao (Eds.), Encyclopedia of Social Science Research Methods (pp. 106-107). SAGE Publications.

Higher Education Research Institute. (1996). A social change model of leadership development: Guidebook version III. National Clearinghouse for Leadership.

Jacoby, B. (1996). Service-learning in higher education: Concepts and practices. The Jossey-Bass Higher and Adult Education Series. Jossey-Bass Publishers.

Jardine, H. E. \& Friedman, L.A. (2017). Using undergraduate facilitators for active learning in organic chemistry: A preparation course and outcomes of the experience. Journal of Chemical Education, 94, 703709.

Katsioloudes, V., \& Cannonier, N. (2019). Investing in critical leadership development with undergraduate students: A qualitative examination of a semester-long internship. Journal of Leadership Education, 18(4).

Keating, K., Rosch, D. M., \& Burgoon, L. (2014). Developmental readiness for leadership: The differential effects of leadership courses on creating "ready, willing, and able" leaders. Journal of Leadership Education, 13(3), 1-16.

Kezar, A. \& Moriarty, D. (2000). Expanding our understanding of student leadership development: A study exploring gender and ethnic identity. Journal of College Student Development, 41, 55-68.

Kuh, G. D. (2008). Excerpt from high-impact educational practices: What they are, who has access to them, and why they matter. $A A C \& U, 19-34$.

Micari, M., Streitwieser, B., \& Light, G. (2005). Undergraduates leading undergraduates: Peer facilitation in a science workshop program. Innovative Higher Education, 30(4), 269-288.

Nora, A., \& Crisp, G. (2007). Mentoring students: Conceptualizing and validating the multi-dimensions of a support system. Journal of College Student Retention: Research, Theory \& Practice, 9(3), 337-356.

Otero, V., Pollock, S., \& Finkelstein, N. (2010). A physics department's role in preparing physics teachers: The Colorado learning assistant model. American Journal of Physics, 78(11), 1218-1224.

Philipp, B., Tretter, T.R., \& Rich, C.V. (2016). Development of undergraduate teaching assistants as effective instructors in STEM courses. Journal of College Science Teaching, 45(3), 74-82

Raykov, T., \& Marcoulides, G. (2011). Classical item analysis using latent variable modeling: A note on a direct evaluation procedure. Structural Equation Modeling, 18(2), 315-324.

Rosch, D. (2018). Examining the (lack of) effects associated with leadership training participation in higher education. Journal of Leadership Education, 17(4), 169-184.

Schalk, K. A., McGinnis, J. R., Harring, J. R., Hendrickson, A. \& Smith, A. C. (2009). The undergraduate teaching assistant experience offers opportunities similar to the undergraduate research experience. Journal of Microbiology \& Biology Education, 10(1), 32-42.

Skipper, T.L. \& Keup, J.R. (2017) The perceived impact of peer leadership experiences on college academic performance. Journal of Student Affairs Research and Practice, 54(1), 95-108. 
Soria, K. M., \& Johnson, M. (2017). High-impact educational practices and the development of college students' pluralistic outcomes. College Student Affairs Journal, 35(2), 100-116.

Tenney, A., \& Houck, B. (2004). Learning about leadership: Team learning's effect on peer leaders. Journal of College Science Teaching, 33(6), 25-29. 